\title{
Relevant analyses of pathogenic bacteria and inflammatory factors in neonatal purulent meningitis
}

\author{
BING SONG ${ }^{1}$, QINGLI HUA ${ }^{2}$, HONGWEI SUN ${ }^{1}$, BINGYU HU $^{1}, \mathrm{XIN} \mathrm{DONG}^{3}$ and LI SUN ${ }^{4}$ \\ Departments of ${ }^{1}$ Pediatrics and ${ }^{2}$ Anesthesiology, Daqing Longnan Hospital; ${ }^{3}$ General Practice, \\ Longgang Street Longnan Community Health Service Center; ${ }^{4}$ Department of Rehabilitation, \\ Daqing Longnan Hospital, Daqing, Heilongjiang 163453, P.R. China
}

Received November 28, 2017; Accepted May 22, 2018

DOI: $10.3892 /$ etm.2018.6276

\begin{abstract}
Pathogenic bacteria and inflammatory factors in neonatal purulent meningitis (PM) were investigated to explore the diagnostic value of inflammatory factors in PM, to clarify the etiology, and to provide evidence for rational clinical treatment. Seventy-four neonates who were diagnosed with PM and were bacteriogically positive in Daqing Longnan Hospital from January 2012 to December 2015 were retrospectively analyzed and used as observation group. Another 74 neonates simultaneously hospitalized with non-PM factors were selected as control group. The levels of C-reactive protein $(\mathrm{CRP})$ and $\beta 2$ microglobulin ( $\beta 2 \mathrm{MG})$ in cerebrospinal fluid in pediatric patients were measured, and the separation culture and identification of pathogenic bacteria were carried out at the same time. The results showed that i) neonatal PM often lacked specific clinical manifestations; ii) high risk factors of neonatal PM included gestational age, body weight $<2,500 \mathrm{~g}$, neonatal asphyxia, premature rupture of membranes, and umbilical or pulmonary infection; iii) the levels of CRP and $\beta 2 \mathrm{MG}$ in the cerebrospinal fluid in the neonatal PM group were significantly higher than those in the control group $(\mathrm{P}<0.05)$, and the neonatal PM group had obviously decreased levels of CRP and $\beta 2 \mathrm{MG}$ in the cerebrospinal fluid after treatment compared with those before treatment $(\mathrm{P}<0.05)$; iv) the positive rate of Gram-negative bacilli (G-bacilli) showed an increasing trend year by year in the past 4 years. Seventy-four strains of bacteria were isolated from the cerebrospinal fluid in neonatal PM group, including 45 strains of Gram-positive cocci (G+cocci, accounting for $60.81 \%$ ) and 29 strains of G-bacilli (accounting for $39.19 \%$ ). Among them, the top three were Escherichia coli, coagulase-negative staphylococci (CNS) and Streptococcus. These findings indicated that for
\end{abstract}

Correspondence to: $\mathrm{Dr} \mathrm{Li}$ Sun, Department of Rehabilitation, Daqing Longnan Hospital, 35 Aiguo Road, Daqing, Heilongjiang 163453, P.R. China

E-mail: sunli1036@163.com

Key words: neonatal purulent meningitis, neonate, pathogenic bacteria, CRP, $\beta 2 \mathrm{MG}$ suspected PM pediatric patients with high risk factors, the inflammatory factors in cerebrospinal fluid and the etiology should be investigated via lumbar puncture as early as possible to confirm the diagnosis. Pathogenic bacteria of meningitis mainly are Escherichia coli, CNS and Streptococcus, and the characteristics of pathogenic bacteria should be considered during experiential medication. The incidence rate of PM due to Streptococcus has an upward tendency and great damage, needing to arouse high attention in clinic.

\section{Introduction}

Neonatal purulent meningitis (PM) is a kind of meningitis in fetuses caused by bacterial infection within 4 weeks after birth. It has high incidence rate and mortality. Survival infants may have neural sequelae of varied degrees, which seriously endangers the life and health of perinatal infants. Early and effective treatment is of great significance in reducing the mortality and sequelae of pediatric patients. However, clinical manifestations of neonatal PM in the early stage are nonspecific. Therefore, early diagnosis has become a thorny issue. In recent years, cytokines have become an active issue of study to neonatologist researchers. Understanding the high risk and predisposing factors of neonatal PM, and the inflammatory factors and pathogenic bacteria in cerebrospinal fluid, and confirming diagnoses early, are helpful to take effective measures to prevent its occurrence, and have a profound significance for the reduction of pediatric patient mortality and the improvement of the short-term and long-term quality of life of neonates. By studying the pathogenic bacteria and inflammatory factors of neonatal PM, this study aimed to provide the basis for rational clinical treatment.

\section{Patients and methods}

Clinical data. Seventy-four PM neonates, who had complete clinical data and were treated in Daqing Longnan Hospital from January 2012 to December 2015, were collected as observation group. All these neonates met the diagnostic criteria of PM. In the observation group, there were 52 males and 22 females aged 1-28 days (with a mean of $19.13 \pm 8.74$ days), with a gestational age of 28-42 weeks (of which 32 neonates 
were $<32$ weeks, 25 neonates were $32-37$ weeks, and 17 neonates were $\geq 37$ weeks), and a birth weight of 1,285-4,570 g (with an average weight of $3,592 \pm 658 \mathrm{~g}$, including $<2,500 \mathrm{~g}$ in 20 neonates and $\geq 2,500 \mathrm{~g}$ in 54 neonates); 28 neonates had premature rupture of membranes, 40 neonates had intrapartum asphyxia, and 6 neonates had amniotic fluid turbidity. There were 13 early-onset neonates (within 3 days after birth) and 61 were late-onset (during 4-28 days after birth). Control group included 74 neonates hospitalized with non-PM during the same period, including 20 neonates with infectious pneumonia, 14 neonates with septicemia, 10 neonates with asphyxia, 10 neonates with jaundice, 6 neonates with respiratory distress syndrome, 5 neonates with hypoxic ischemic encephalopathy, 4 neonates with umbilical infection, 3 neonates with amniotic fluid aspiration, and 2 neonates with meconium aspiration. Among them, 51 neonates were male and 23 neonates were female; the age in days was 1-28 days, with an average of $19.17 \pm 9.02$ days; the gestational age was $28-42$ weeks, of whom 17 neonates were $<32$ weeks, 40 neonates were 32-37 weeks, and 17 neonates were $\geq 37$ weeks; 10 neonates were $<2,500 \mathrm{~g}$ in birth weight, and 64 neonates were $\geq 2,500 \mathrm{~g}$ in birth weight; 4 neonates had premature rupture of membranes, 14 neonates had intrapartum asphyxia, and 1 neonate had amniotic fluid turbidity. The study was approved by the Ethics Committee of Daqing Longnan Hospital (Daqing, China) and written informed consents were signed by the patient's guardians.

Inclusion and exclusion criteria. Inclusion criteria: i) neonates with the clinical manifestations of neonatal PM (symptoms: abnormal body temperature, milk refusal, convulsion, and abnormal reaction; signs: intracranial hypertension performance); ii) neonates whose results in cerebrospinal fluid routine examination and biochemical test were in line with PM changes; iii) neonates who had positive pathogens in cerebrospinal fluid or blood culture. Exclusion criteria: i) neonates who had positive fungi in cerebrospinal fluid or blood culture; ii) neonates who were positive in cerebrospinal fluid or blood culture but the samples might have been contaminated.

\section{Methods}

Records of general data. Records of general data includes abortion history and age of the mother of the pediatric patient, and sex, age, birth weight and gestational age of the pediatric patient, as well as the occurrence of premature rupture of membranes, intrapartum asphyxia, umbilical or pulmonary infection.

Detection of inflammation indexes in cerebrospinal fluid. A total of $2 \mathrm{ml}$ of cerebrospinal fluid was collected from all pediatric patients via strict aseptic operation, and sent to clinical laboratory of the hospital for bacterial culture and identification which were performed by a specialist. Operations were conducted in accordance with related quality indexes. Additional cerebrospinal fluid was taken for the detection of inflammation indexes $[\beta 2$ microglobulin $(\beta 2 \mathrm{MG})$ and $\mathrm{C}$-reactive protein (CRP)]. All operations were carried out strictly according to the instructions.

Statistical analysis. Statistical Product and Service Solutions (SPSS) 18.0 software (SPSS Inc., Chicago, IL, USA) was used for data analysis. $\chi^{2}$ test was adopted for enumeration data comparison among groups. Normal measurement data were recorded as mean \pm standard deviation, and t-test was employed for comparison among groups. $\mathrm{P}<0.05$ was considered to indicate a statistically significant difference.

\section{Results}

Clinical manifestations of neonatal PM. Neonatal PM might have no symptoms in early stage, and lack specific clinical manifestations. The main symptoms of neonatal PM were fever, reduced milk-intake, milk refusal or vomiting and sleepiness or dysphoria, among which, fever or low body temperature accounted for $74.32 \%(55 / 74)$, reduced milk-intake accounted for $63.51 \%$ (47/74), milk refusal or vomiting accounted for $45.95 \%$ (24/74), sleepiness or dysphoria accounted for $33.78 \%$ (25/74), cyanosis accounted for $29.73 \%$ (22/74), and convulsion accounted for 20.27 (15/74). The main signs were low spirit, jaundice, irregular respiration, bregma stress and dystonia. Among them, short of vigour occupied $95.95 \%$ (71/74), jaundice $70.27 \%(52 / 74)$, irregular respiration $62.16 \%(46 / 74)$, bregma stress $39.24 \%$ (35/74), dystonia 48.65\% (36/74), and eye anomaly occupied $28.38 \%(21 / 74)$ (Figs. 1 and 2).

Analyses of high risk factors. The results showed that the high risk factors of neonatal PM were not significantly correlated with abortion history and age of the mother of the pediatric patient, sex of the pediatric patient, and delivery mode, but obviously related to the premature rupture of membranes, premature birth, body weight $<2,500 \mathrm{~g}$, neonatal asphyxia, and umbilical or pulmonary disease of the pediatric patient, respectively, suggesting that neonates with premature rupture of membranes before birth, younger gestational age and lower body weight are more susceptible to PM infection (Table I).

Comparison of inflammatory indicators between two groups of neonates. The results revealed that the average of CRP in cerebrospinal fluid in the neonatal PM group was $23.51 \pm 12.63 \mathrm{mg} / \mathrm{l}$ and that in the control group was $1.01 \pm 0.78 \mathrm{mg} / \mathrm{l}$; the mean of $\beta 2 \mathrm{MG}$ in cerebrospinal fluid was $4.82 \pm 0.95 \mathrm{mg} / \mathrm{l}$ in the neonatal PM group and $0.80 \pm 0.56 \mathrm{mg} / \mathrm{l}$ in the control group; neonatal PM group had overtly increased levels of CRP and $\beta 2 \mathrm{MG}$ compared with those in the control group $(\mathrm{P}<0.05)$ (Table II). In the neonatal $\mathrm{PM}$ group, the CRP levels in cerebrospinal fluid after treatment for 1,2 and 3 weeks were $10.26 \pm 7.42,4.78 \pm 3.36$ and $1.36 \pm 0.85 \mathrm{mg} / 1$, respectively, and the levels of $\beta 2 \mathrm{MG}$ were $2.15 \pm 0.84,1.23 \pm 0.67$, and $0.82 \pm 0.51 \mathrm{mg} / 1$, respectively. Compared with those before treatment, CRP and $\beta 2 \mathrm{MG}$ levels in cerebrospinal fluid in the neonatal PM group were obviously reduced after treatment for 1,2 and 3 weeks $(\mathrm{P}<0.05)($ Fig. 3$)$.

Composition of bacterial strain detected in the past four years. During 2012-2015, there was an upward tendency in positive rate of Gram-negative bacilli (G-bacilli) year by year, and the positive rates were $28.75,33.33,40.00$ and $40.91 \%$, respectively; however, the positive rate of Gram-positive cocci (G+cocci) showed a decline trend year by year, and the positive rates were 71.43, 66.67, 60.00 and 59.09\%, respectively (Fig. 4). 


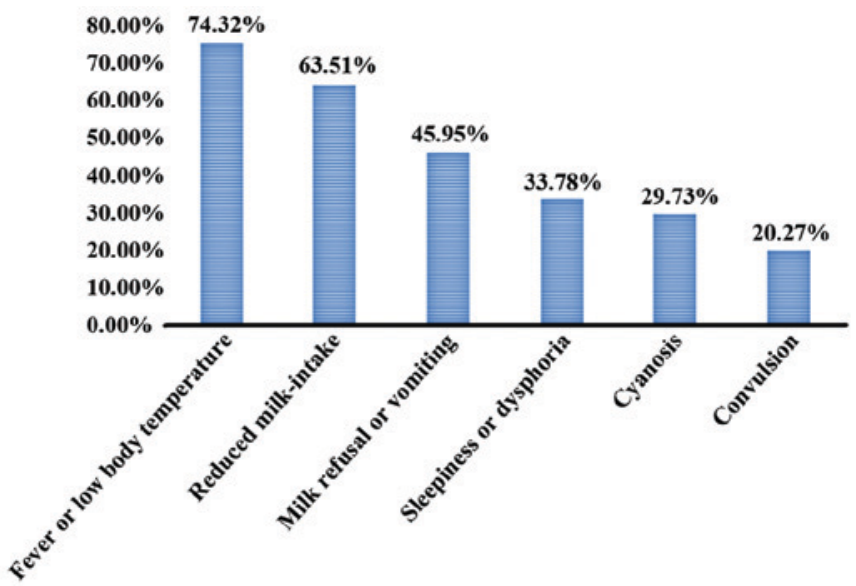

Figure 1. Symptom constituent ratio of neonatal PM (\%). The composition ratio of the main symptoms is: $74.32 \%$ of fever or body temperature rise, $63.51 \%$ reduction of milk consumption, $45.95 \%$ of refusal of milk or vomiting, $33.78 \%$ of drowsiness or irritability, $29.73 \%$ of cyanosis, and $20.27 \%$ of convulsions. PM, purulent meningitis.

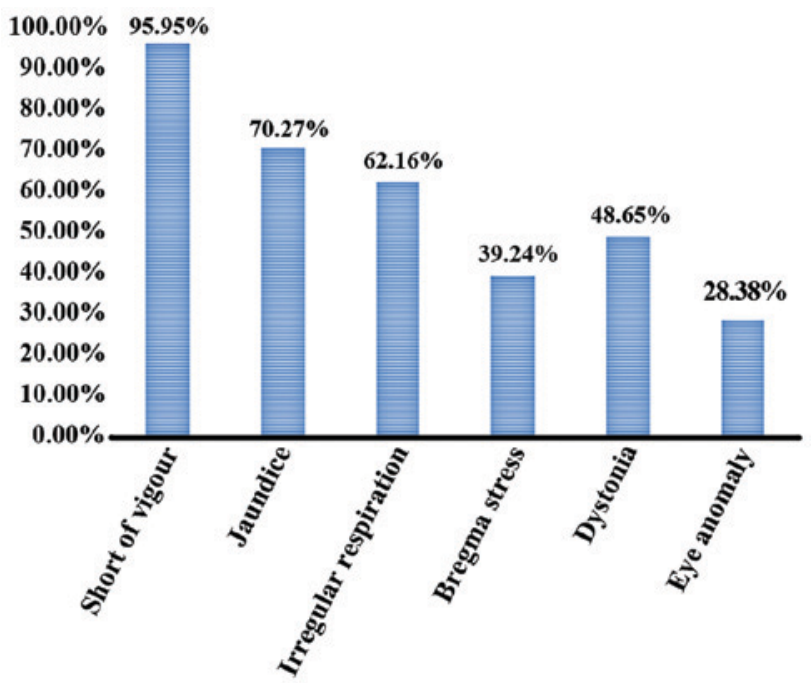

Figure 2. Sign constituent ratio of neonatal PM (\%). The composition ratio of major signs: $95.95 \%$ of mental difference, $70.27 \%$ of jaundice, $62.16 \%$ of irregular breathing, $39.24 \%$ of prestrain tension, $48.65 \%$ of dystonia and $28.38 \%$ of eye abnormalities. PM, purulent meningitis.

Composition of pathogenic bacteria. Single bacterial strain was found in all cerebrospinal fluid samples of the 74 neonates who were diagnosed with PM and were bacteriologically positive. All of them were aerobic bacteria. Among them, 45 strains were $\mathrm{G}+\mathrm{cocci}$, which accounted for $60.81 \%$ and included 13 strains of coagulase-negative staphylococci (CNS) (17.57\%), 7 strains of Staphylococcus aureus (9.46\%), 15 strains of Streptococcus [20.27\%, including 12 strains of group B Streptococcus (GBS, 4 strains were detected in 2012-2013, and 8 strains were detected in 2014-2015)], and 10 strains of Enterococcus (13.51\%); 29 strains were G-negative bacilli, accounting for $39.19 \%$ and including 21 strains of Escherichia coli (28.39\%), 3 strains of Acinetobacter (4.05\%), 1 strain of Pseudomonas (1.35\%) and 4 strains of Klebsiella (5.41\%). The top three were successively Escherichia coli, CNS and Streptococcus (Fig. 5).
Table I. Analyses of predisposing factors between two groups of neonates.

\begin{tabular}{lccc}
\hline Observation & PM group Control group & $\mathrm{t} / \chi^{2}$ \\
factor & $(\mathrm{n}=74)$ & $(\mathrm{n}=74)$ & value
\end{tabular}

Abortion history

of the mother

$\begin{array}{lllll}\text { No } & 49 & 47 & 1.912 & 0.132 \\ \text { Yes } & 25 & 27 & & \\ \begin{array}{l}\text { Age of the mother } \\ \text { (years) }\end{array} & & & & \\ <35 & 46 & 50 & 2.134 & 0.089 \\ \geq 35 & 28 & 24 & & \end{array}$

Sex of the

pediatric patient

$\begin{array}{lrrrr}\text { Male } & 52 & 51 & 1.429 & 0.178 \\ \text { Female } & 22 & 23 & & \\ \begin{array}{l}\text { Delivery mode } \\ \text { Spontaneous delivery }\end{array} & 51 & 53 & 1.623 & 0.151 \\ \begin{array}{l}\text { Forceps or fetal } \\ \text { aspiration delivery }\end{array} & 5 & 4 & & \\ \text { Cesarean delivery } & 18 & 17 & & \end{array}$

Premature rupture of membranes

$\begin{array}{lrrr}\text { No } & 46 & 70 & 15.413<0.001 \\ \text { Yes } & 28 & 4 & \end{array}$

Gestational age

(weeks)

$\begin{array}{lll}<32 & 32 & 17 \\ 32-37 & 25 & 40 \\ \geq 37 & 17 & 17 \\ \text { Body weight }(\mathrm{g}) & & \\ \quad<2,500 & 20 & 10 \\ \geq 2,500 & 54 & 64 \\ \text { Neonatal asphyxia } & & \\ \text { No } & 34 & 60 \\ \text { Yes } & 40 & 14\end{array}$

$11.645 \quad 0.003$

40

10

8.7320 .006

64

60

$12.208 \quad 0.001$

Umbilical or

pulmonary infection

\begin{tabular}{lllll} 
No & 31 & 50 & 9.536 & 0.005 \\
Yes & 43 & 24 & & \\
\hline
\end{tabular}

PM, purulent meningitis.

Table II. Comparisons of inflammatory indicators between two groups of neonates.

\begin{tabular}{lcccc}
\hline $\begin{array}{l}\text { Indicator } \\
(\mathrm{mg} / \mathrm{l})\end{array}$ & $\begin{array}{c}\text { Observation } \\
\text { group } \\
(\mathrm{n}=74)\end{array}$ & $\begin{array}{c}\text { Control } \\
\text { group } \\
(\mathrm{n}=74)\end{array}$ & $\begin{array}{c}\mathrm{t} / \chi^{2} \\
\text { value }\end{array}$ & P-value \\
\hline $\begin{array}{l}\mathrm{CRP} \text { in } \\
\text { cerebrospinal fluid }\end{array}$ & $23.51 \pm 12.63$ & $1.01 \pm 0.78$ & 15.792 & 0.001 \\
$\begin{array}{l}\beta 2 \mathrm{MG} \text { in } \\
\text { cerebrospinal fluid }\end{array}$ & $4.82 \pm 0.95$ & $0.80 \pm 0.56$ & 11.834 & 0.005 \\
\hline
\end{tabular}

CRP, C-reactive protein; $\beta 2 \mathrm{MG}, \beta 2$ microglobulin. 


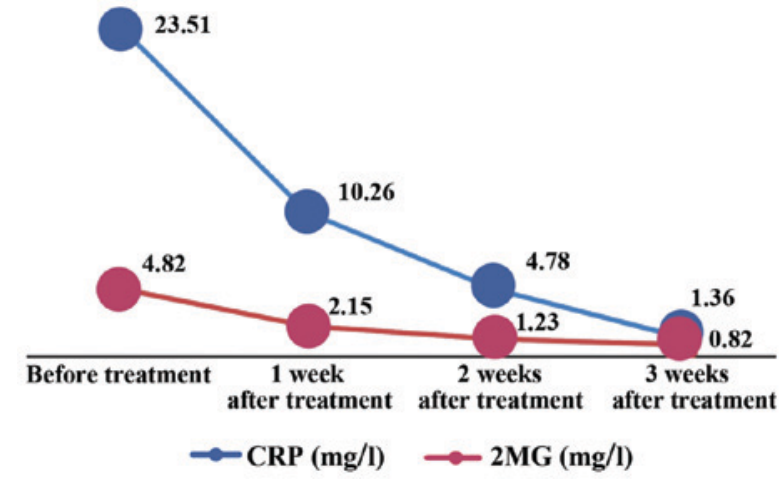

Figure 3. Fluctuations of $\mathrm{CRP}$ and $\beta 2 \mathrm{MG}$ levels in cerebrospinal fluid in neonatal PM group after treatment. Compared with CRP and $\beta 2 M G$ levels before treatment, CRP and $\beta 2 \mathrm{MG}$ levels in cerebrospinal fluid in neonatal PM group were obviously reduced after treatment for 1,2 and 3 weeks $(\mathrm{P}<0.05)$. CRP, C-reactive protein; $\beta 2 \mathrm{MG}, \beta 2$ microglobulin; PM, purulent meningitis.

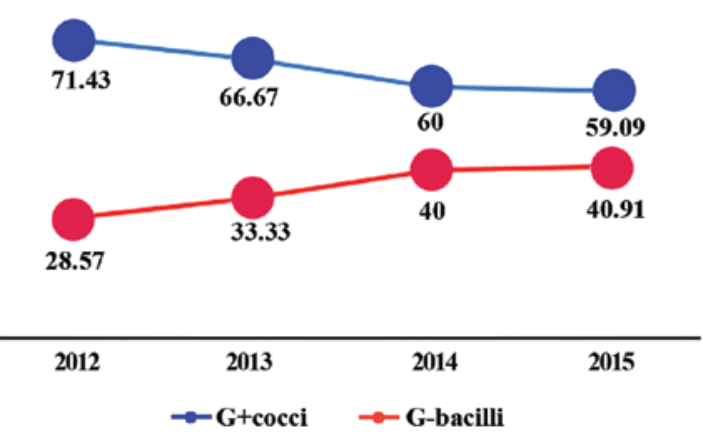

Figure 4. Tendency chart of G-bacilli and G+cocci detected in 4 years (\%). The detection rate of G-bacilli increased year by year from 2012 to 2015, while the detection rate of $\mathrm{G}+$ decreased year by year. G-bacilli, Gram-negative bacilli; G+cocci, Gram-positive cocci.

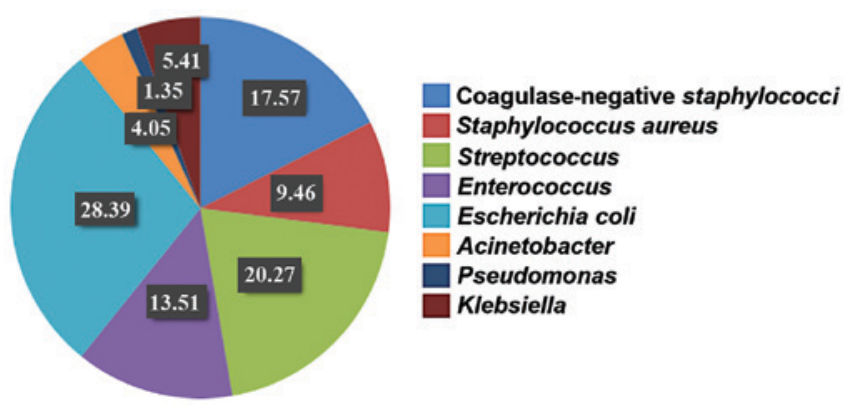

Figure 5. Constituent ratio of pathogenic bacteria (\%). Coagulase-negative staphylococci accounts for $17.57 \%$, Staphylococcus aureus $9.46 \%$, Streptococcus 15 strains $20.27 \%$, Escherichia $28.39 \%$, Acinetobacter $4.05 \%$, Pseudomonas $1.35 \%$, and Klebsiella accounts for $5.41 \%$. The top three pathogenic bacteria are: Escherichia coli, CNS and Streptococcus. CNS, coagulase-negative staphylococci.

Comparison of pathogenic bacteria composition between early-onset and late-onset neonatal PM. Streptococcic (mainly GBS) accounted for the largest proportion in pathogenic bacteria of early-onset neonatal PM, which was $\sim 30.77 \%$ $(4 / 13)$ and higher than that in pathogenic bacteria of late-onset neonatal PM $\left[14.75 \%(9 / 61), \chi^{2}=5.278 ; \mathrm{P}<0.05\right]$. CNS was frequently found in pathogenic bacteria of late-onset neonatal PM was $\sim 9.67 \%$ (12/61), which was higher than that in patho-
Table III. Comparison of pathogenic bacteria composition between early-onset and late-onset neonatal PM (cases, \%).

\begin{tabular}{lccc}
\hline Bacterial strain & Cases & Early-onset & Late-onset \\
\hline Total & 74 & 13 & 61 \\
CNS & 13 & $1(7.69)$ & $12(19.67)^{\mathrm{a}}$ \\
Staphylococcus aureus & 7 & $2(15.38)$ & $5(8.20)$ \\
Streptococcus & 15 & $4(30.77)$ & $11(18.03)^{\mathrm{b}}$ \\
Enterococcus & 10 & $1(7.69)$ & $9(14.75)$ \\
Escherichia coli & 21 & $3(23.08)$ & $18(29.51)$ \\
Acinetobacter & 3 & $1(7.69)$ & $2(3.28)$ \\
Pseudomonas & 1 & $0(0.00)$ & $1(1.64)$ \\
Klebsiella & 4 & $1(7.69)$ & $3(4.92)$ \\
\hline
\end{tabular}

${ }^{\mathrm{a}} \mathrm{P}<0.05$, compared with the composition ratio of CNS in early-onset cases; ${ }^{\mathrm{b}} \mathrm{P}<0.05$, compared with composition ratio of Streptococcus (mainly GBS) in early-onset cases. PM, purulent meningitis; CNS, coagulase-negative staphylococci.

genic bacteria of early-onset neonatal PM [7.69\% (1/13), $\left.\chi^{2}=4.631 ; \mathrm{P}<0.05\right]$. Although Escherichia coli accounted for the largest proportion in pathogenic bacteria of early-onset neonatal PM, at $29.51 \%$ (18/61), it was not statistically significant from that in pathogenic bacteria of early-onset neonatal PM [23.08\% (3/13), $\left.\chi^{2}=2.512 ; \mathrm{P}>0.05\right]$ (Table III).

\section{Discussion}

Clinical manifestations of neonatal PM. In comparison with other age groups of children, neonates have open fontanel and cranial suture, insufficient muscular strength in the neck, low immunity and poor blood brain barrier function, so they are more susceptible to PM (1). Most pediatric patients just have the symptoms of bloodstream infections, such as low to moderate fever, milk refusal, hypokinesia, and subenergetic crying; neonatal PM has unobvious intracranial hypertension signs and lacks typical meningeal irritation signs, which easily leads to delaying diagnosis and improper treatment, resulting in a high fatality rate (2). According to the results in this study, 74 neonates with PM showed no specific clinical manifestations, with fever in 55 neonates $(74.32 \%)$ and reduced milk-intake in 47 neonates $(63.51 \%)$, which is in line with reports of Chang et al and Lin et al $(3,4)$. As to signs, there were low spirit (71 cases, $95.95 \%)$, jaundice (52 cases, $70.27 \%$ ), irregular respiration, bregma stress and abnormal muscle tension. Therefore, once the pediatric patients have clinical symptoms including fever, milk refusal, low spirit and jaundice, strongly vigilant observation and treatment are needed against the complication of PM, and lumbar puncture should be considered, so as to make clear diagnoses, avoiding missed diagnoses and mis-diagnoses, and reduce mortality and sequelae.

High risk factors of neonatal PM. Studies have found that neonatal PM infection is mainly related to three ways (5). The first way is antepartum infection, which is mainly caused by maternal factors; if mothers are infected with bacteremia before delivery, the neonates may be infected through 
placental circulation. The second way is intrapartum infection, which often occur in patients with premature rupture of membranes; with a long time of delivery, plus relaxed disinfection in the midwifery, the neonates are infected by swallowing or inhaling the infected amniotic fluid. The third way is postnatal infection, which is caused by the invasion of pathogenic bacteria into blood circulation and then meninx via natural orifice, umbilicus, damaged skin and mucosa. A study indicated that (6) neonates are susceptible to infections due to poor overall immune function (cellular immunity and humoral immunity); because of imperfect blood-brain barrier, the infections are not easy to be limited, and the bacteria can easily penetrate the blood-brain barrier to cause intracranial infections. Therefore, PM is often a part of septicemia or is secondary to septicemia. Scholars have considered that (7) neonates who are suspected of septicemia in clinical practice should receive cerebrospinal fluid examination, no matter whether the high-risk factors, neural symptoms and signs of PM are found or not. The results showed that the high-risk factors of PM were gestational age, weight $<2,500 \mathrm{~g}$, neonatal asphyxia, premature rupture of membranes, and umbilical or pulmonary infection. Kavuncuoğlu et al (8) reported that the incidence rate of neonatal PM gradually was increased along with the decreases of gestational age and birth weight curve. Severe asphyxia not only reduces the immune function of the body, but also damages the blood-brain barrier. If the delivery time is too long, and the disinfection is not strict in the process of midwifery, pediatric patients with premature rupture of membranes may be infected by swallowing or inhaling contaminated amniotic fluid.

Inflammatory factors of neonatal PM. The major pathogenesis of patients with PM is the infiltration or aggregation of a large number of neutrophil in peripheral blood and cerebrospinal fluid, which plays an important role in the removal of bacterial infections, but may induce local (meningeal) inflammatory injuries. CRP is a nonspecific reaction product in acute phase of inflammatory diseases, and is not significantly affected by various factors including anti-inflammatory or immunosuppressive agents, fever, erythrocyte sedimentation rate, and leukocyte increase. Clinically, CRP detection is an index of important value during the treatment of inflammatory diseases (9), and it is an item that can be used to assess whether the body is infected and whether the disease is in the active stage (10). The results in this study revealed that CRP level in neonatal PM group was significantly higher than that in control group $(\mathrm{P}<0.05)$, and had a certain value for auxiliary diagnosis. However, Enguix et al (11) reported that CRP has low specificity and sensitivity to the diagnosis of severe infectious diseases. Therefore, CRP concentration cannot be used as a separate indicator for the evaluation of intracranial infection. Bacterial infections in other parts of the body should be firstly excluded, and other tests of cerebrospinal fluid should be combined. $\beta 2 \mathrm{MG}$ is synthesized by lymphocytes, which is located on the surface of all nucleated cells and may be elevated in inflammation. The results in this study showed that the level of $\beta 2 \mathrm{MG}$ in neonatal PM group was overtly higher than that in the control group $(\mathrm{P}<0.05)$, and the levels of CRP and $\beta 2 \mathrm{MG}$ in cerebrospinal fluid after treatment were evidently lower $(\mathrm{P}<0.05)$, which is consistent with a literature report (12). The increase of $\beta 2 \mathrm{MG}$ in cerebrospinal fluid in neonatal PM group may come from: i) central nervous system, once the immune system in nervous system is activated, intrathecal $\beta 2 \mathrm{MG}$ syntheses and cells in cerebrospinal fluid are increased, and metabolic cycles are accelerated, thereby a large number of $\beta 2 \mathrm{MG}$ fall off from the cell surface and enter into the cerebrospinal fluid; ii) periphery, $\beta 2 \mathrm{MG}$ in blood may enter into the cerebrospinal fluid through the damaged blood-brain barrier (13). Therefore, a comprehensive analysis on increases of CRP and $\beta 2 \mathrm{MG}$ in cerebrospinal fluid can support the diagnosis of neonatal PM.

Changes in the pathogenic bacteria of neonatal PM. Due to different regions, years and age grades, plus the abuse of antibiotics in great quantities in clinical practice along with constant launches of new antibacterial drugs, the strain of pathogenic bacteria is changing continuously, bringing difficulties to the diagnosis and treatment, which is one of the important causes of neonatal death (14). In developed countries, GBS is the primary pathogenic bacterium of neonatal PM, followed by G-negative bacilli. In developing countries, although G-negative bacilli and Staphylococcus aureus remain dominant, the incidence rate of GBS meningitis is also increasing gradually (15-17). Studies have shown that streptococci, enterococci, Escherichia coli and other G-negative bacilli can cause a mortality of up to $10 \%$, and no significant differences were found among these strains, which is similar to the existing report (18). This study indicated that the top 3 pathogens that form the neonatal PM in order were: Escherichia coli, CNS and Streptococcus. In China, it was considered that neonatal GBS infection is rare, but in recent years, the prevalence rate of GBS infection in our department has been enhanced year by year. In this study, there were 15 cases of Streptococcus, in which 12 cases were GBS, with only 4 strains in 2012-2013 and 8 strains in 2014-2015, needing to arouse attention in clinical work. Some studies have reported that prognosis of neonatal GBS PM and different GBS serums are related, among which type III serum is closely related to meningitis and its severity (19). This is because that type III GBS has a strong adhesion capacity on vascular endothelial tissue, chorion and neonatal lungs, which is difficult to be eliminated. It is deemed that GBS infection is mainly related to mother GBS colonization, especially early-onset infection (20). European and American countries use universal screening methods to prevent perinatal mother-to-infant GBS infection, and achieve remarkable results, namely neonatal early-onset PM septicemia can be reduced by nearly $90 \%$ (21). As the incidence rate of GBS in this region shows an upward trend, and once being infected, the consequence is severe, and a heavy burden is placed on families and society, it is necessary to perform a large-sample epidemiological survey on GBS colonization of pregnant and delivery women in this region. In early-onset cases, the top 2 pathogenic bacteria are Streptococcus and Escherichia coli. Streptococcus is the first cause, mainly correlated with vertical transmission after mother vaginal colonization. In late-onset cases, Escherichia coli is often found, followed by CNS. The high incidence of CNS in late-onset cases is deemed to be related with the large number of Staphylococcus in the external environment exposed to pediatric patients. The incidence of streptococci has an increasing trend, frequently found 
in early-onset cases, and has poor prognosis, which should arouse high attention of clinical practice.

\section{Acknowledgements}

Not applicable.

\section{Funding}

No funding was received.

\section{Availability of data and materials}

The datasets used and/or analyzed during the present study are available from the corresponding author on reasonable request.

\section{Authors' contributions}

BS, QH and LS conceived and designed the study. HS, BH and XD were responsible for the collection and analysis of the patient data. BS and $\mathrm{QH}$ interpreted the data and drafted the manuscript. LS revised the manuscript critically for important intellectual content. All authors read and approved the final study.

\section{Ethics approval and consent to participate}

The study was approved by the Ethics Committee of Daqing Longnan Hospital (Daqing, China). Signed informed consents were obtained from the guardians.

\section{Consent for publication}

Not applicable.

\section{Competing interests}

The authors declare that they have no competing interests.

\section{References}

1. Klingenberg C, Olomi R, Oneko M, Sam N and Langeland N: Neonatal morbidity and mortality in a Tanzanian tertiary care referral hospital. Ann Trop Paediatr 23: 293-299, 2003.

2. El Bashir H, Laundy M and Booy R: Diagnosis and treatment of bacterial meningitis. Arch Dis Child 88: 615-620, 2003.

3. Chang CJ, Chang WN, Huang LT, Huang SC, Chang YC, Hung PL, Tasi CY, Lu CH, Cheng BC, Lee PY, et al: Neonatal bacterial meningitis in southern Taiwan. Pediatr Neurol 29 288-294, 2003
4. Lin PC, Chiu NC, Li WC, Chi H, Hsu CH, Hung HY, Kao HA and Huang FY: Characteristics of nosocomial bacterial meningitis in children. J Microbiol Immunol Infect 37: 35-38, 2004.

5. Ruan L, Wu D, Li X, Huang Q, Lin L, Lin J, Chen L, Xu P, Jin J, Yang N, et al: Analysis of microbial community composition and diversity in postoperative intracranial infection using high throughput sequencing. Mol Med Rep 16: 3938-3946, 2017.

6. Rahman S: Lumbar puncture in neonates under and over 72 hours of age. J Coll Physicians Surg Pak 17: 646-647, 2007.

7. Hoque MM, Ahmed ASMNU, Chowdhury MAKA, Darmstadt GL and Saha SK: Septicemic neonates without lumbar puncture: What are we missing? J Trop Pediatr 52: 63-65, 2006.

8. Kavuncuoğlu S, Gürsoy S, Türel Ö, Aldemir EY and Hosaf E: Neonatal bacterial meningitis in Turkey: Epidemiology, risk factors, and prognosis. J Infect Dev Ctries 7: 73-81, 2013.

9. Gambino R: C-reactive protein - undervalued, underutilized. Clin Chem 43: 2017-2018, 1997.

10. Smith RP and Lipworth BJ: C-reactive protein in simple community-acquired pneumonia. Chest 107: 1028-1031, 1995.

11. Enguix A, Rey C, Concha A, Medina A, Coto D and Diéguez MA: Comparison of procalcitonin with C-reactive protein and serum amyloid for the early diagnosis of bacterial sepsis in critically ill neonates and children. Intensive Care Med 27: 211-215, 2001.

12. Takahashi S, Oki J, Miyamoto A, Moriyama T, Asano A, Inyaku $\mathrm{F}$ and Okuno A: Beta-2-microglobulin and ferritin in cerebrospinal fluid for evaluation of patients with meningitis of different etiologies. Brain Dev 21: 192-199, 1999.

13. Murawska E, Szychowska Z and Jarno A: Beta 2 microglobulin in children with neuroinfections. Przegl Epidemiol 51: 457-463, 1997 (In Polish).

14. Sáez-Llorens X and McCracken GH Jr: Bacterial meningitis in children. Lancet 361: 2139-2148, 2003.

15. Lin MC, Chi H, Chiu NC, Huang FY and Ho CS: Factors for poor prognosis of neonatal bacterial meningitis in a medical center in Northern Taiwan. J Microbiol Immunol Infect 45: 442-447, 2012.

16. Cho HK, Lee H, Kang JH, Kim KN, Kim DS, Kim YK, Kim JS, Kim JH, Kim CH, Kim HM, et al: The causative organisms of bacterial meningitis in Korean children in 1996-2005. J Korean Med Sci 25: 895-899, 2010.

17. Furyk JS, Swann O and Molyneux E: Systematic review: Neonatal meningitis in the developing world. Trop Med Int Health 16: 672-679, 2011.

18. Gaschignard J, Levy C, Romain O, Cohen R, Bingen E, Aujard Y and Boileau P: Neonatal bacterial meningitis: 444 cases in 7 years. Pediatr Infect Dis J 30: 212-217, 2011.

19. Levent F, Baker CJ, Rench MA and Edwards MS: Early outcomes of group B streptococcal meningitis in the 21 st century. Pediatr Infect Dis J 29: 1009-1012, 2010.

20. Barichello T, Fagundes GD, Generoso JS, Elias SG, Simões LR and Teixeira AL: Pathophysiology of neonatal acute bacterial meningitis. J Med Microbiol 62: 1781-1789, 2013.

21. Verani JR, McGee L and Schrag SJ; Division of Bacterial Diseases, National Center for Immunization and Respiratory Diseases, Centers for Disease Control and Prevention (CDC): Prevention of perinatal group B streptococcal disease - revised guidelines from CDC, 2010. MMWR Recomm Rep 59: 1-36, 2010.

This work is licensed under a Creative Commons Attribution-NonCommercial-NoDerivatives 4.0 International (CC BY-NC-ND 4.0) License. 